\title{
Pendidikan Kesehatan tentang Kesiapan Identitas pada Remaja di Parak Gadang Timur, Andalas Padang
}

\author{
Rika Sarfika, Uci Ramadhani Anwar, dan Feri Fernandes \\ Fakultas Keperawatan, Universitas Andalas, Kampus Limau Manis, Padang, 25163. Indonesia \\ E-mail: rikasarfika@nrs.unand.ac.id
}

Keywords:

adolescents,

growth and

development,

health education,

identity readiness

Kata Kunci:

kesiapan

identitas,

pendidikan

kesehatan,

remaja, tumbuh

kembang

\begin{abstract}
Adolescence is a period of attaining identity. If it fails, then Identity Confusion will occur. For adolescents to grow into great generations and vigorous self-defense, adolescents need to achieve optimal identity development. This program aims to stimulate adolescent growth and development to make the readiness of growth and development of identity in adolescents. The activity was carried out on November 27, 2019, at junior high school students at SMPN 9 Padang. A total of 29 teenagers attended the health education provided with lecture and stimulation methods. Before and after attending health education, adolescents fill out questionnaires containing five questions about adolescent knowledge of adolescent growth and development. Knowledge data were processed using t-dependent tests to determine changes in teenage knowledge scores before and after attending health education. The activities showed that the average score of knowledge of adolescents before being given health education was 2.72 and after being given health education was 4.31. Paired sample $t$-test results showed the value of $P v=0.000$, meaning that there was a significant change between adolescents' knowledge before and after being given health education. Based on the results, it is recommended for nurses at the public health center to continue to conduct health education and socialization about adolescents' growth and development to increase the readiness of adolescent psychosocial growth and development.
\end{abstract}
ABSTRAK
Masa remaja merupakan masa pencapaian identitas, jika gagal maka akan terjadi kebingungan identitas (Identity Confusion). Agar remaja tumbuh menjadi generasi yang hebat dan ketahanan diri yang kuat, maka remaja perlu mencapai perkembangan identity yang optimal. Tujuan pengabdian ini adalah memberikan stimulasi tumbuh kembang pada remaja sebagai upaya mencapai kesiapan tumbuh kembang identity pada remaja. Pelaksanaan kegiatan dilakukan pada tanggal 27 November 2019 pada remaja siswa di SMPN 9 Padang. Sebanyak 29 anak remaja hadir mengikuti pendidikan kesehatan yang diberikan dengan metode ceramah dan demonstrasi. Sebelum dan setelah mengikuti pendidikan kesehatan, remaja mengisi kuesioner yang berisi 5 pertanyaan tentang pengetahuan remaja terhadap tumbuh kembang usia remaja. Data pengetahuan diolah menggunakan uji t-dependent untuk mengetahui perubahan skor pengetahuan remaja sebelum dan setelah mengikuti pendidikan kesehatan. Hasil kegiatan menunjukkan bahwa skor rata-rata pengetahuan remaja sebelum diberikan pendidikan kesehatan sebesar 2,72 dan setelah diberikan pendidikan kesehatan sebesar 4.31. Hasil uji paired sample t-test menunjukkan nilai $\mathrm{Pv}=0.000$, artinya terdapat perubahan yang signifikan antara pengetahuan remaja sebelum dan setelah diberikan pendidikan kesehatan. 
Berdasarkan hasil, maka direkomendasikan bagi perawat di Puskesmas untuk terus melakukan pendidikan kesehatan dan sosialisasi tentang pertumbuhan dan perkembangan remaja untuk meningkatkan kesiapan pertumbuhan dan perkembangan psikososial remaja.

\section{PENDAHULUAN}

Kesehatan jiwa adalah kondisi dimana seorang individu dapat berkembang secara fisik, mental, spiritual dan sosial sehingga individu tersebut menyadari kemampuan sendiri, dapat mengatasi tekanan, dapat bekerja secara produktif, dan mampu memberikan konstribusi untuk komunitasnya (UU RI Nomor 18 tentang Kesehatan Jiwa). Kesehatan jiwa mencakup disetiap perkembangan individu dimulai sejak dalam kandungan kemudian dilanjutkan ke tahap selanjutnya yang dimulai dari bayi (0-18 bulan), masa toddler (1,5-3 tahun), masa anak-anak awal atau pra sekolah (3-6 tahun), usia sekolah (6-12 tahun), remaja (12-18 tahun), dewasa muda (18-35 tahun), dewasa tengah (35-65 tahun), sehingga dewasa akhir (>65 tahun) (Wong, D.L, 2009).

Remaja (adolescence) adalah penduduk dalam rentang usia 10-19 tahun, dimana pada masa ini ditandai dengan perkembangan psikososial identity versus identity confusion. Remaja yang sehat berusaha membentuk dan memperlihatkan identitas diri dan ciri-ciri yang khas dari dirinya. Dorongan ini seringkali dilakukan dengan sangat ekstrim dan berlebihan, sehingga tidak jarang dipandang oleh lingkungannya sebagai penyimpangan atau kenakalan. Dorongan pembentukan identitas diri yang kuat di satu pihak, sering diimbangi oleh rasa setia kawan dan toleransi yang besar terhadap kelompok sebayanya. Diantara kelompok sebaya mereka mengadakan pembagian peran, dan seringkali mereka sangat patuh terhadap peran yang diberikan kepada masing-masing anggota (Potter \& Perry, 2012). Namun apabila tumbuh kembang ini tidak tercapai dengan baik, maka dapat berdampak buruk pada fase kehidupan selanjutnya. Remaja dapat menjadi individu yang tidak percaya diri, kecemasan sosial, harga diri rendah, perilaku agresif, dan bahkan bisa jatuh pada perilaku kriminal.

Menurut WHO diperkirakan jumlah remaja di dunia sebanyak 1,2 milyar atau 18\% dari jumlah penduduk dunia. Menurut data Statistik Indonesia tahun 2014 jumlah remaja di Indonesia sebanyak 14.392.649 jiwa sedangkan jumlah remaja di Sumatera Barat sebanyak 443.014 jiwa. Jumlah remaja di Kota Padang sebanyak 107.565 jiwa. Jumlah remaja di Kecamatan Parak Gadang Timur sebanyak 6.374 jiwa, dan jumlah remaja di Kelurahan Parak Gadang Timur sebanyak 663 jiwa (BKKBN, 2011). Pada tahun 2035, Indonesia akan mendapatkan bonus demografi, artinya remaja yang ada saat ini akan menjadi individu yang produktif. Oleh karena itu, remaja harus menjadi perhatian bersama agar remaja dapat tumbuh menjadi generasi yang sehat jiwa yang akan melanjutkan perjuangan dan cita-cita bangsa ke depannya.

Berdasarkan studi pendahuluan di RW VIII, Kelurahan Parak Gadang Timur Kecamatan Andalas, Kota Padang didapatkan data bahwa jumlah penduduk di Parak Gadang Timur sebanyak 9152 jiwa dengan jumlah remaja sebanyak 663 jiwa. Pada RW VIII jumlah penduduk saat ini 1024 jiwa yang terdiri dari $261 \mathrm{KK}$ dengan jumlah KK pada RT 01 sebanyak 70 KK, RT 02 sebanyak 49 KK, RT 03 sebanyak 34 KK, RT 04 sebanyak 65 KK, dan RT 05 sebanyak 52 KK. Berdasarkan hasil wawancara dengan kader kesehatan jiwa didapatkan informasi bahwa belum ada kegiatan semacam pendidikan kesehatan atau penyuluhan tentang tumbuh kembang pada remaja. Remaja adalah aset bangsa yang harus dijaga dan diperhatikan dengan baik agar dapat bertumbuh dan berkembang menjadi individu dewasa yang produktif dan berkualitas. Oleh karena itu, perlu dilakukan suatu upaya prevensi kesehatan agar dapat meningkatkan 
pengetahuan dan pemahaman remaja tentang tugas perkembangannya secara optimal.

Berdasarkan latar belakang di atas, maka tujuan kegiatan ini adalah memberikan pendidikan kesehatan untuk meningkatkan kesiapan identitas diri pada remaja di Parak Gadang Timur. Diharapkan kegiatan ini dapat meningkatkan pengetahuan dan pemahaman remaja tentang tugas perkembangan pada usianya saat ini dan cara menstimulasinya, sehingga dapat mencegah kebingungan identitas (identity confusion) pada remaja.

\section{METODE}

Kegiatan ini dilakukan di RW VIII Kelurahan Parak Gadang Timur Kecamatan Andalas Padang pada tanggal 27 November 2019. Kegiatan ini bekerjasama dengan Puskesmas Andalas dan Yayasan Pelita Jiwa Insani yang bergerak dalam bidang rehabilitasi medik pada orang dengan penyalahgunaan NAPZA. Metode pendidikan kesehatan yang diberikan yaitu menggunakan pendekatan ceramah dan demonstrasi, adapun materi yang diberikan mengenai pengertian remaja, karakteristik tumbuh kembang remaja, karakteristik tumbuh kembang sehat dan tidak sehat, cara menstimulasi tumbuh kembang pada remaja. Peran Yayasan Pelita Jiwa Insani yaitu memberikan edukasi mengenai NAPZA dan dampaknya terhadap kesehatan jiwa remaja. Kegiatan ini difasilitasi oleh SMPN 9 Padang. Guru mengidentifikasi siswa dan menyediakan kelas untuk pelaksanaan kegiatan. Pendidikan kesehatan dalam mengidentifikasi peserta yang terlibat kegiatan sesuai kriteria dan menggerakkan peserta untuk mengikuti kegiatan.

Kegiatan berlangsung selama 90 menit yang berlangsung di salah satu kelas sekolah SMPN 9 Padang. Jumlah peserta sebanyak 29 orang yang berasal dari siswa kelas IX. Kegiatan diawali dengan pengukuran pengetahuan peserta tentang tumbuh kembang remaja (pre-test) dalam bentuk kuesioner yang terdiri dari 5 item pertanyaan tentang tumbuh kembang remaja. Kegiatan pre-test ini dilakukan selama 10 menit. Kemudian kegiatan dilanjutkan dengan pembukaan kegiatan oleh Kepala Sekolah SMPN 9 Padang, pihak puskesmas dan ketua panitia selama 15 menit. Selanjutnya, kegiatan dilanjutkan dengan pemberian pendidikan kesehatan materi pertama tentang tumbuh kembang remaja dengan metode ceramah dan demonstrasi yang berlangsung selama 45 menit, kemudian dilanjutkan materi kedua oleh Yayasan Pelita Jiwa Insani tentang penyalahgunaan NAPZA dan dampaknya terhadap kesehatan jiwa remaja selama 30 menit. Setelah itu, pada tahap akhir kegiatan dilakukan pengukuran pengetahun kedua (posttest) yang berlangsung selama 10 menit dengan menggunakan alat ukur yang sama pada saat pre-test untuk melihat perubahan pengetahuan remaja setelah diberikan pendidikan kesehatan. Data hasil pre-test dan post-test kemudian data diolah menggunakan uji paired t-test.

\section{HASIL DAN PEMBAHASAN}

Kegiatan pemberian edukasi mengenai stimulasi tumbuh kembang pada remaja siswa di SMPN 9 Padang telah berhasil dilakukan pada tanggal 27 November 2019. Bentuk kegiatan dapat dilihat pada Gambar 1. Kegiatan dilakukan selama 90 menit yang diikuti oleh 29 orang peserta.

Berdasarkan analisis statistik, didapatkan hasil bahwa skor rerata pengetahuan peserta sebelum diberikan pendidikan kesehatan sebesar 2,72 dengan nilai minimum 2 dan maksimum 5. Sedangkan setelah diberikan pendidikan kesehatan, skor pengetahuan peserta menjadi 4,31 dengan nilai minimum 3 dan maksimum 5. Hasil analisis ini dapat dilihat pada Tabel 1. 

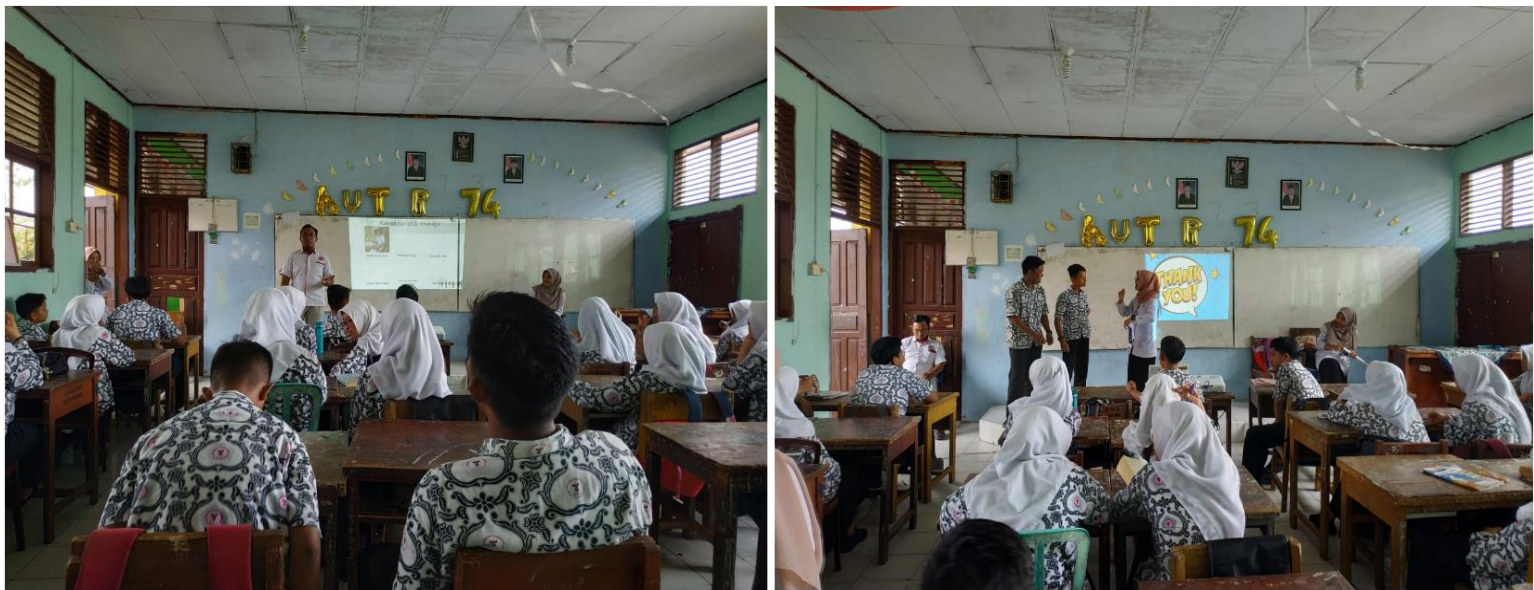

Gambar 1. Pemberian edukasi tentang NAPZA oleh Yayasan Pelita Jiwa Insani dan demonstrasi stimulasi tumbuh kembang

Tabel 1. Skor rerata pengetahuan peserta tentang tumbuh kembang remaja pada saat pre-test dan post-test pada remaja di SMPN 9 Padang.

\begin{tabular}{cccc}
\hline Pengetahuan & n & Min-Max & Mean \\
\hline Pre test & 29 & $2-5$ & 2,72 \\
Post test & 29 & $3-5$ & 4,31 \\
\hline
\end{tabular}

Pada Tabel 2 dapat dilihat bahwa hasil uji paired t-test didapatkan nilai $\mathrm{P}=0,000(\mathrm{Pv}<\alpha)$, artinya terdapat perbedaan yang signifikan pengetahuan remaja tentang tumbuh kembang sebelum dan setelah diberikan pendidikan kesehatan, dimana selisih skor adalah sebesar 1,586 point. Hasil kegiatan ini sesuai dengan yang diharapkan, dimana pendidikan kesehatan dapat mempengaruhi dan meningkatkan pengetahuan peserta. Hal ini sama dengan penelitian yang dilakukan Hasanah (2017) bahwa terdapat peningkatan pengetahuan keluarga tentang pembentukan identitas diri remaja sebelum dan sesudah diberikan edukasi yaitu dari 14.06\% menjadi 95.31\%.

Tabel 2. Analisis perbedaan pengetahuan peserta sebelum dan setelah diberikan pendidikan kesehatan pada remaja di SMPN 9 Padang.

\begin{tabular}{|c|c|c|c|c|}
\hline \multicolumn{5}{|c|}{ Tingkat Pengetahuan } \\
\hline & $\mathbf{n}$ & Mean & Selisih Mean & p value \\
\hline Pengetahuan sebelum & 29 & 2.72 & 1.586 & 0.000 \\
\hline Pengetahuan sesudah & 29 & 4.31 & & \\
\hline
\end{tabular}

Pemberian pengetahuan melalui metode ceramah dan demonstrasi dapat memudahkan peserta didik untuk menyerap dan memahami informasi yang disampaikan. Penjelasan yang diberikan oleh presentator dengan metode ceramah dan diperkuat dengan penajaman skill psikomotor melalui metode demonstrasi. Metode demonstrasi diberikan dalam bentuk pemberian contoh-contoh cara stimulasi tumbuh kembang yang belum optimal pada remaja. Selain dapat meningkatkan pengetahuan peserta, metode ini juga dapat meningkatkan 
partisipasi peserta dan mendorong peserta untuk aktif dalam kegiatan pembelajaran. Pemberian pendidikan kesehatan ini juga didukung oleh media power point yang digunakan banyak menyajikan contoh-contoh gambar kartun dan animasi sehingga tampilan penyajian tidak membosankan. Selain itu, kegiatan ini juga menggunakan leaflet yang berfungsi sebagai bahan bacaan peserta untuk mengenal tentang karakteristik tumbuh kembang remaja dan alat peraga yang digunakan ketika melakukan demonstrasi. Sehingga, metode dan media yang digunakan ini membuat peserta antusias untuk belajar dan meningkatkan pengetahuannya tentang tumbuh kembang usia remaja.

Stuart dan Laraia (2009) menjelaskan bahwa pendidikan kesehatan dapat menjadi salah satu elemen program perawatan kesehatan jiwa individu dan keluarga dengan cara pemberian informasi, pendidikan kesehatan melalui komunikasi yang terapeutik dan kerjasama dengan individu ataupun keluarga merupakan bagian penting dari stimulasi perkembangan remaja. Jadi, pendidikan kesehatan dapat membantu remaja dalam meningkatkan pengetahuan tentang perkembangan remaja dan cara menstimulasi perkembangan tersebut melalui pemberian informasi dan edukasi yang dapat mendukung pencapaian identitas diri remaja.

Melihat keberhasilan kegiatan ini dalam meningkatkan pengetahuan remaja tentang tumbuh kembang pada usianya, maka kegiatan ini perlu dilakukan secara berkelanjutan agar dapat menghasilkan generasi yang sehat dan berprestasi. Karena kegiatan ini menggunakan metode CMHN dimana kendali kegiatan dipegang oleh perawat yang berada puskesmas, maka kegiatan ini dapat dilanjutkan oleh puskesmas melalui program PKPR dengan bekerjasama dengan pihakpihak sekolah baik sekolah setara SMP maupun setara SMA.

Remaja yang berpengetahuan luas (knowledgeable) akan memiliki sikap dan perilaku yang baik. Ketika pengetahuan sudah terbentuk maka akan terjadi pembentukan identitas diri yang sesuai pada remaja. Identitas diri yang kuat dapat mencegah terjadinya perilaku menyimpang pada remaja, dengan demikian bonus demografi dapat diwujudkan.

\section{KESIMPULAN DAN SARAN}

Pendidikan kesehatan tentang tumbuh kembang remaja dengan menggunakan metode ceramah dan demontrasi dapat meningkatkan pengetahuan remaja tentang tumbuh kembang dan cara menstimulasi tumbuh kembang pada usianya. Maka disarankan pada perawat pemegang program PKPR di Puskesmas untuk dapat melakukan pendidikan kesehatan secara rutin dan berkelanjutan di wilayah kerja puskesmas Andalas sebagai upaya promotif dan preventif dalam mencegah terjadi perilaku menyimpang pada remaja.

\section{DAFTAR PUSTAKA}

Agustiani, H. (2009). Psikologi Perkembangan, Pendekatan dengan Konsep Diri dan Penyesuaian Diri pada Remaja. Bandung : PT. Refika Adiatmika.

BKKBN. 2014. Remaja dan SPN (Seks Pranikah). (Diakses tanggal 15 November 2019).

Friedman, L. M. (2010). Buku ajar keperawatan keluarga: riset, teori, praktik. (5 th ed). Jakarta: EGC. Friedman.M.Bowden, Jones EG. (2014). Family Nursing: Research, Theory \& Practise. USA. Conecticut:Appleton and Lange. 
Hasanah, U. (2017). Pengaruh Terapi Kelompok Terapiutik Remaja dan Psikoedukasi Keluarga Terhadap Perkembangan dan Identitas Diri Remaja. Vol (9). No (1).

Hurlock, E.B. (2005). Perkembangan anak. Jakarta: Erlangga.

Hurlock, Elizabeth B. (2011). Psikologi Perkembangan: Suatu Pendekatan Sepanjang Rentang Kehidupan. Jakarta: Erlangga.

Kemenkes (2012). Profil Kesehatan Indonesia Tahun 2012. Jakarta.

Kementerian Kesehatan RI. (2011). Profil Kesehatan Indonesia 2010. Melalui http://www.depkes.go.id, diakses tanggal 15 Desember 2019.

Maulana, H.D.J. (2009). Promosi Kesehatan. Jakarta : EGC Mohammad Ali dan Mohammad Asrori. (2012) Psikologi Remaja.

Notoatmodjo, S.(2012). Promosi Kesehatan dan Perilaku Kesehatan. Jakarta :Rineka cipta.

Notoatmodjo, Soekidjo. Pendidikan dan Perilaku Kesehatan. Jakarta. Rineka Cipta. 2010. h. 3It's Cancer. USA :Mc-Graw Hill, 272 - 279.

Riset Kesehatan Dasar (Riskesdas). (2013). Badan Penelitian dan Pengembangan Kesehatan Kementerian RI tahun 2013. Jakarta : Badan Litbangkes DepkesSa'id, M, A. (2015). Mendidik Remaja Nakal : Panduan Praktis Seni Mendidik dan Berinteraksi dengan Remaja, Semesta Hikmah. Yogyakarta.

Santrock, John W. (2003). “Adolescene: perkembangan remaja edisi keenam” Alih bahasa: Shinto B. Adelar: Sherly Seragih. Jakarta : Erlangga.

Sarafino, E. P. (2006). Health Psychology: Biopsychosocial Interactions. Fifth Edition. USA: John Wiley \& Sons.

Sarwono, Sarlito W. (2013). Psikologi Remaja Edisi Revisi. Jakarta.

Setiawati, S. (2008). Proses Pembelajaran dalam Pendidikan Kesehatan. Jakarta: Trans Info Media.

Soedjatmiko. (2008). Peranan TPA dalam Upaya Pembinaan Tumbuh Kembang Anak dalam Buku Ajar 2 Tumbuh Kembang Anak dan Remaja. Edisi 1.Jakarta : Sagung Seto.

Soetjiningsih. (2007). Tumbuh Kembang Remaja dan Permasalahannya. Jakarta : Sagung Seto.

Stuart, G.W. (2009). Principles and practice of psychiatric Nursing. 9th ed.

Suliha. (2002). Pendidikan Kesehatan dalam Keperawatan. Jakarta: EGC World Health Organization (WHO). (2010). Child and Adolescent Health and Development: Progress Report 2009. France: WHO Library. 
Townsend, C.M (2009). Essential of Psychiatric Mental Health Nursing. Ed 6th. Philadelphia: F. A Davis Company.

World Health Organization (WHO). (2014). World Health Statistic 2014. WHO Library.

Yudha.dkk. (2005). Pembelajaran Kooperatif untuk Meningkatkan Ketrampilan Anak. Jakarta : Departemen Pendidikan Nasional.

Yusuf. (2008). Psikologi Perkembangan Anak dan Remaja. Bandung : PT Remaja Rosdakarya. 